\title{
Is Two Dimensional Echocardiography sufficient for selection of device for successful transcatheter closure of Patent Ductus Arteriosus in Children?
}

\author{
Manish Shrestha $^{1}$, Urmila Shakya ${ }^{1}$, Poonam Sharma ${ }^{1}$, Subhash Shah ${ }^{1}$, Shilpa Aryal ${ }^{1}$, Amshu Shakya ${ }^{1}$, \\ Shistata Rajbhandari ${ }^{3}$, Vidhata KC ${ }^{1}$, Kul Ratna Thapa ${ }^{1}$, Chandra Mani Adhikari ${ }^{2}$ \\ 'Department of Pediatric Cardiology, Shahid Gangalal National Heart Centre, Kathmandu, Nepal \\ ${ }^{2}$ Department of Cardiology, Shahid Gangalal National Heart Centre, Kathmandu, Nepal \\ ${ }^{3}$ Department of Dermatology, Om Hospital and Research Centre, Kathmandu, Nepal
}

\author{
Corresponding Author: Manish Shrestha \\ Department of Pediatric Cardiology, \\ Shahid Gangalal National Heart Centre, Kathmandu, Nepal \\ Email:maaniche@gmail.com \\ ORCID ID NO: 0000-0001-8290-0368
}

Cite this article as: Shrestha M., Shakya U., Sharma P., et al. Is Two Dimensional Echocardiography sufficient for selection of device for successful transcatheter closure of Patent Ductus Arteriosus in Children? Nepalese Heart Journal 2021; Vol 18(2), 45-48.

Submission date: 28 th August, 2021

Accepted date: 3 th October, 2021

\section{Abstract}

Background and Aims: Two dimensional transthoracic echocardiography (2DE) is widely used for detecting congenital heart disease and is possible to obtain precise measurement of Patent ductus arteriosus (PDA) for device selection required for transcatheter closure. Primary aim of the study is to determine whether echocardiographic assessment alone can be used for selection of device for transcatheter closure of PDA.

Methods: Children with PDA and planned for transcatheter intervention were included in this cross-sectional study of one year. PDA was assessed with 2DE and prediction of device size was made.

Results: The results were obtained from 107 children. The median age and weight at intervention were 3.8 years (ranging from 6 months to 14 years) and $12 \mathrm{~kg}$ (ranging from 3.5 to $60 \mathrm{~kg}$ ). Type A (Conical) PDA was the commonest PDA morphology accounting for $87.8 \%$ and $85 \%$ in $2 \mathrm{DE}$ and angiography respectively. There was no difference $(\mathrm{p}<0.05)$ in the narrowest diameter at pulmonary end measured by 2DE and angiography, however ampulla diameter and ductal length were statistically different $(p=0.95)$. The predicted size of device by 2 DE was discordant $(p<0.05)$ to the actual device used in a total study population, however when patients with severe pulmonary hypertension, non-type A and larger PDA (narrowest diameter > $6 \mathrm{~mm})$ were excluded, the predicted size of device by $2 \mathrm{DE}$ was statistically concordant $(\mathrm{p}=0.1)$ to the actual device used in $89(83 \%)$ patients.

Conclusion: Two dimensional Transthoracic echocardiography alone may be helpful in choosing the device during transcatheter closure of PDA in selective group of patients.

Keywords: Device, Echocardiography, Patent ductus arteriosus, transcatheter closure

DOI: https://doi.org/10.3126/njh.v18i2.40404

\section{Introduction}

Patent ductus arteriosus (PDA) is a common congenital heart disease (CHD) in children accounting for $\sim 5-10 \%$ of all CHDs ${ }^{1}$. Currently, transcatheter closure is the modality of choice in most cases for closure of $\mathrm{PDA}^{2,3}$. The standard way of performing transcatheter closure is by obtaining both arterial and venous accesses ${ }^{4}$.

Cardiac catheterization via arterial access, especially in small children weighing less than $10 \mathrm{~kg}$, usually brings minor to major complications like prolong bleeding, groin hematoma and decrease to absent distal pulses. This causes distal perfusion compromise which ultimately lead to increase dose of heparin, prolong sedation time, prolong procedural time, prolong hospital stay and increase $\operatorname{cost}^{5-8}$.

Two-dimensional transthoracic echocardiography (2DE) is a noninvasive, easily accessible, convenient, reproducible and inexpensive tool used widely for screening and follow-up examinations before and after PDA closure. The recent advancement in echocardiography with its improved resolution makes it possible to obtain precise measurements for adequate device selection required for transcatheter closure. Moreover, the risk of ductal spasm during the intervention is also unlikely.

Successful transcatheter closure depends on selecting appropriate device according to the size and shape of the PDA. The size and 
shape of the PDA are conventionally determined by the aortogram done during the procedure where the minimum diameter at the pulmonary end, the ampulla diameter and the ductal length is measured. Angiogram is considered gold standard for ductal size and morphology. However, if 2DE is able to reproduce all those variables with precise measurements, aortogram via femoral artery puncture could be avoided in many patients. Various studies comparing PDA measurements between 2DE and Angiogram has shown mixed results ${ }^{1,8-10}$. Hence, this study was done to determine whether echocardiographic measurement correlate with angiographic measurement and if echocardiography alone can be used for device selection successfully.

\section{Methods}

A cross-sectional study was done for one year from October 2017 to September 2018 in Shahid Gangalal National Heart Centre (SGNHC), Kathmandu, a tertiary referral centre of Nepal. Children less than 15 years of age with the diagnosis of PDA and plan for transcatheter closure were included. Children of less than three months of age, weight less than three $\mathrm{kg}$ and PDA co-existing with other heart diseases like ventricular septal defect, atrial septal defect, coarctation of aorta etc. were excluded. Minimum Sample size for the study was calculated to be 109. Ethical approval was obtained from Institutional review board before initiation of study and informed written consent was taken from the parents/guardians.

Patients who were planned for catheter-based intervention were admitted one day prior to procedure. Echocardiography of all cases was done with Philips Epiq7 and findings were recorded by two pediatric cardiologists who had discussed earlier to make measurement uniform so that subjective variation in measurement could be reduced. PDA morphology and size were assessed in parasternal short axis (PSAX) view, high parasternal (ductal) view and suprasternal view. The pulmonary end, the aortic end and the length of the duct were measured (Figure 1). Based on the 2DE evaluation, the predicted device type and size to be used to occlude PDA were recorded. Patients demographic profile and clinical findings were recorded in a predesign proforma.

During transcatheter procedure, aortic angiogram at the expected level of PDA was performed by pigtail catheter in lateral projection and reassessment of morphology and size of PDA was done. It was made sure that the interventionist was not the same person who did $2 \mathrm{DE}$ and was unaware of $2 \mathrm{DE}$ report and predicted device. After the intervention, the required data including the device type and size were recorded.

PDA can be classified into five types based on Krichenko angiographic classification. ${ }^{11}$ Type $\mathrm{A}$ is a conical ductus with prominent aortic ampulla and constriction at the pulmonary artery end like a funnel; Type B is a wide and short ductus, also called windowlike ductus; Type $\mathrm{C}$ is a tubular ductus without any constriction; Type $\mathrm{D}$ is a complex ductus with multiple constrictions and Type $\mathrm{E}$ is an elongated ductus with constriction far from the anterior edge of the trachea. However, in 2DE, Type E ductus was defined as a long, tortuous duct that requires more than one echocardiographic plane to be completely imaged ${ }^{12}$.

All the collected data were entered into the statistical software SPSS version 23 (SPSS, Inc, Chicago, IL). Continuous variables were expressed as mean \pm SD or median with range as appropriate and discrete variables were presented as frequencies and/or percentages. For comparative analysis, paired T-test or Chi-square test was used and $p$ value less than 0.05 was considered significant.

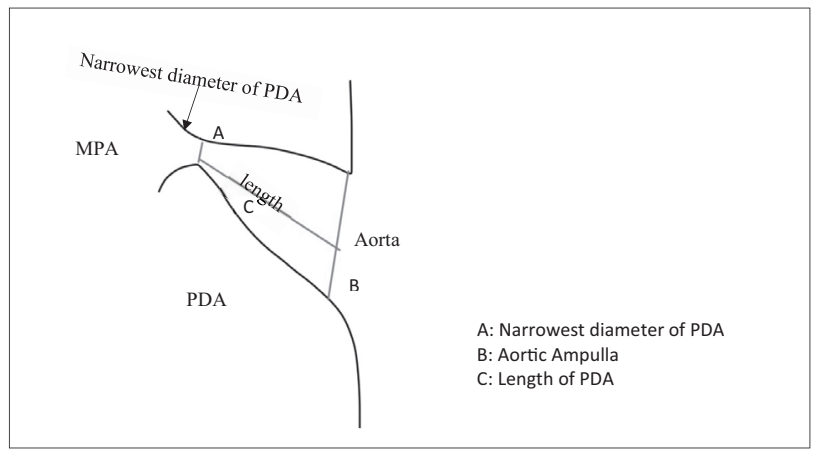

Schematic diagram of PDA with site of measurements

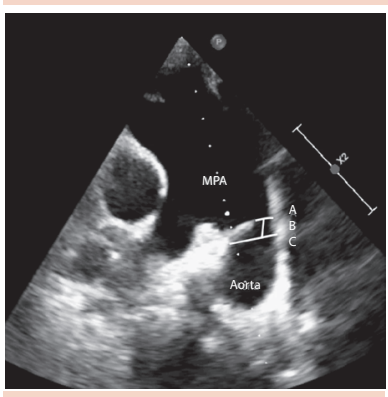

PDA from 2D TTE

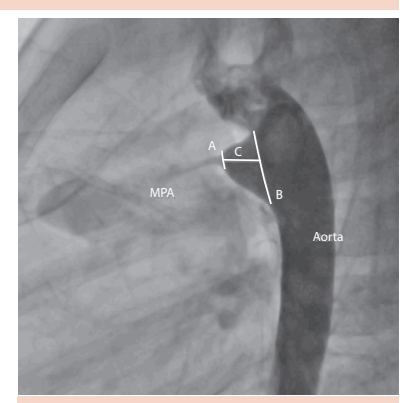

PDA from Angiogram
Figure 1: PDA, where and how it is measured

\section{Results}

Data from 107 children were included in the analysis and two had to be excluded due to incomplete data. Baseline characteristics and hemodynamic data are shown in Table 1 . The pulmonary arterial pressure in $23(21.5 \%)$ children was more than half systemic arterial pressure.

Table 1: Baseline Characteristics

\begin{tabular}{|l|l|}
\hline \multicolumn{1}{|c|}{ Variables } & \multicolumn{1}{c|}{ Results } \\
\hline Age (median with range) & $\begin{array}{l}3.8 \text { years }(6 \text { months }- \\
14 \text { years) }\end{array}$ \\
\hline Female (n) & $78(72.9 \%)$ \\
\hline Weight (median with range) & $12 \mathrm{~kg}(3.5-60 \mathrm{~kg})$ \\
\hline $\begin{array}{l}\text { Mean Pulmonary Artery Pressure } \\
\text { (median with range) }\end{array}$ & $32(15-85) \mathrm{mmHg}$ \\
\hline $\begin{array}{l}\text { Classification according to PA } \\
\text { pressure* }\end{array}$ & $65(60.7 \%)$ \\
\hline • Normal & $19(17.8 \%)$ \\
\hline - Mild & $9(8.4 \%)$ \\
\hline$\bullet$ Moderate & $14(13.1 \%)$ \\
\hline$\bullet$ Severe & \\
\hline
\end{tabular}

$P A$, pulmonary artery.

*pulmonary artery pressure is classified based on ratio of systemic arterial pressure of the individual.

The morphology and measurements of PDA are shown in table 2.

The mean size of narrowest diameter at the pulmonary end of PDA in 2DE and angiogram were $4.2 \pm 1.3 \mathrm{~mm}$ and $4.2 \pm 1.8 \mathrm{~mm}$ respectively. There was no statistically significant difference $(\mathrm{p}=$ 
$0.95)$ between the two measurements and they have a strong positive correlation $(\mathrm{r}=0.9, \mathrm{p}<0.001)$.

There was a statistically significant difference between aortic end mean diameter in $2 \mathrm{DE}$ and angiogram $(\mathrm{p}=0.02)$ which were $11.8 \pm 3.7 \mathrm{~mm}$ and $12.7 \pm 4.1 \mathrm{~mm}$ respectively, however there was a positive correlation between the two measurements $(\mathrm{r}=0.5$, $\mathrm{p}<0.001$ ). Similarly there was a statistically significant difference between the mean length of PDA in 2DE and angiogram $(p=0.03)$ which were $8.1 \pm 2.3 \mathrm{~mm}$ and $8.8 \pm 3.5 \mathrm{~mm}$ respectively which also had a positive correlation $(\mathrm{r}=0.4, \mathrm{p}<0.001)$.

Table 2: Morphology and Measurements of PDA

\begin{tabular}{|lccc}
\hline & 2 D TTE & Angiography & \\
\hline PDA morphology & & & \\
\hline - Conical (Type A) & $94(87.8 \%)$ & $91(85 \%)$ & \\
\hline - Window (Type B) & $1(0.9 \%)$ & $1(0.9 \%)$ & \\
\hline - Tubular (Type C) & $6(5.6 \%)$ & $6(5.6 \%)$ & \\
\hline - Complex (Type D) & $1(0.9 \%)$ & $2(1.9 \%)$ & \\
\hline - Elongated (Type E) & $4(3.7 \%)$ & $7(6.5 \%)$ & \\
\hline - Unidentified & $1(0.9 \%)$ & - & \\
\hline PDA dimensions (mm) (mean with SD \& range) & & \\
\hline Pulmonary end & $4.2 \pm$ & $4.2 \pm 1.8$ & 0.95 \\
\hline Aortic end & $1.3(2.3-10)$ & $(1.7-11.7)$ & \\
\hline Length & $\begin{array}{c}11.8 \pm \\
12.7 \pm 4.1\end{array}$ & 0.02 \\
\hline
\end{tabular}

PDA, Patent Ductus Arteriosus; 2 D TTE, Two dimensional Trans Thoracic Echocardiography

Type A (conical) PDA was the most common morphology both in 2DE (87.8\%) and Angiogram (85\%). There was discordant of morphology in seven $(6.5 \%)$ cases. One patient in 2DE which was difficult to define (unidentified) came to be "complex" (type D) in angiogram. Three patients with "elongated" (type E) PDA in angiogram were visualized as "conical" (type A) PDA in 2DE.

All the children had successful device closure of PDA. Regular (conical shaped) PDA occluder like Amplatzer Duct Occluder (ADO, Abbott structural heart, Illinois, USA) was used in all except for one case in which cylindrical type of PDA occluder (Memopart PDA occluder, Lepu Medical, Beijing, China) was used. The commonest size of the device used was $8 / 6(46.7 \%)$ followed by $10 / 8(29.9 \%)$ (Table 3).

Table 3: Size of the devices

\begin{tabular}{|c|c|}
\hline Size of the device $(\mathrm{mm})$ & Frequency (percentage) \\
\hline $6 / 4$ & $5(4.7)$ \\
\hline $8 / 6$ & $50(46.7)$ \\
\hline $10 / 8$ & $32(29.9)$ \\
\hline $12 / 10$ & $13(12.1)$ \\
\hline $14 / 12$ & $3(2.8)$ \\
\hline $16 / 14$ & $1(0.9)$ \\
\hline $18 / 16$ & $1(0.9)$ \\
\hline $20 / 18$ & $1(0.9)$ \\
\hline$* 8$ & $1(0.9)$ \\
\hline
\end{tabular}

*cylindrical type of device having both aortic and pulmonary end $8 \mathrm{~mm}$.
There was statistically significant difference $(p=0.006)$ in the predicted size of the device via 2DE measurements when compared to the actual size of the device used to occlude PDA. However, when the patients with severe pulmonary hypertension, non-type A PDA and the narrowest diameter of PDA more than $6 \mathrm{~mm}$ were excluded, the predicted size of the device via 2DE was statistically comparable to the size of the actual device used to occlude PDA $(p=0.1)$ in 89 patients.

\section{Discussion}

In this study done among 107 children, there was no statistical difference among the narrowest diameter of PDA measured by angiogram and 2-D transthoracic echocardiogram. In addition, although the predicted size of device selected was significantly different, the difference was not significant after excluding patients with severe pulmonary hypertension, non-type A morphology and those with narrowest diameter of more than $6 \mathrm{~mm}$.

Hiraishi et al. back in the year 1991, demonstrated "when angiograms were of adequate quality, echocardiographic images showed ductal morphologies closely resembling those of the respective angiograms" and they concluded that the combination of two-dimensional and Doppler echocardiography to be a highly specific method for evaluating patency and morphology of a ductus arteriosus $^{13}$. In the present study, 2DE successfully identified $94 \%$ of PDA morphology. This study supports Ramacioti et al., ${ }^{12}$ that Type E (Elongated) PDA is sometimes difficult to differentiate from Type A (conical) PDA in 2DE as both have similar shape but they differ in length. Application of color Doppler is very useful for diagnosing PDA, however many studies showed that color Doppler often overestimates the minimum size (narrowest end) of PDA which is the main basis for selecting the appropriate occluder ${ }^{10,14,15}$.

This study showed almost similar narrowest diameter at pulmonary end between $2 \mathrm{DE}$ and angiographic measurements $(\mathrm{p}=$ $0.95)$ with strong positive correlation $(r=0.9, p<0.001)$, however the aortic end and ductal length measured by $2 \mathrm{DE}$ were smaller than those measured by angiogram but there was a positive correlation in both the measurements. PDA narrowest diameter is the most important determining factor to select the size of the device. The most commonly and readily available device in our country is ADO type of PDA device which is usually selected so that the smaller end of the device is at least $2 \mathrm{~mm}$ larger than the narrowest diameter of the PDA. Knowing the aortic ampulla beforehand is always an ease for the interventionist to plan which device to select and what approach to take. If there is roomy ampulla, taking one size larger device may not cause any harm. In the contrary if there is almost no ampulla (e.g. window or tubular type of PDA), there is a risk of causing iatrogenic coarctation post device occlusion. Moreover, as these kind of PDA are usually associated with high pulmonary artery (PA) pressure, it is mandatory to assess the change in post PDA occlusion PA pressure and difference in ascending and descending aorta pressures to rule out iatrogenic coarctation.

The present study had $85 \%$ patient with type A PDA which justified the Krichenko Classification ${ }^{11}$ that it is the commonest morphology of PDA. This conical PDA has a narrow waist (at the pulmonary end) and a definite ampulla which make the procedure relatively safe. PDA with larger diameter is usually expansile and adding 2 to $4 \mathrm{~mm}$ to the narrowest diameter may not be optimum and sometimes needed to oversize by 1.5 to 2 times. In the present study when the predicted size of device by $2 \mathrm{DE}$ was compared with the actual device in the total study population, there was a significant difference $(\mathrm{p}<0.05)$ but when the patients with severe pulmonary hypertension, non-type A PDA and waist of PDA more than $6 \mathrm{~mm}$ were excluded, the predicted size by $2 \mathrm{DE}$ was comparable $(\mathrm{p}=0.1)$ to the actual size of the device. Patients with pulmonary hypertension, type B and type C PDA always pose a special challenge to the 
interventionist. They are usually large without definite waist hence it is always advisable to obtain both arterial and venous access to perform the procedure in these subsets of patients.

This is a single centre study with a limited number of cases. Also the possibility of inter observer variability among the two pediatric cardiologists involved was not assessed. Although the study has showed similar narrowest diameter in both echocardiography and angiography measurement, further study based on transcatheter PDA closure with echocardiography assessment alone without arterial puncture is recommended.

\section{Conclusion}

Two dimensional Transthoracic echocardiography alone may be helpful in choosing the device during trancatheter closure of PDA in selective group of patients.

\section{Conflict of Interest and Financial Disclosure}

The authors have nothing to disclose.

\section{References}

1. Elsheikh RG, Darweish AZ, Elsetiha M, Kamel H. Comparative study between real time three dimensional echocardiogram and angiography in evaluation of patent ductus arteriosus, single center experience. J Saudi Heart Assoc. 2014 Oct; 26 (4): 204-211

2. Feltes TF, Bacha E, Beekman RH III, Cheatham JP et al. Indications for cardiac catheterization and intervention in pediatric cardiac disease: A scientific statement from the American Heart Association. Circulation. 2011;123:26072652.

3. Saxena A, Relan L, Aggarwal R, Awasthy N et al., Guidelines for the management of common congenital heart diseases: A consensus statement on indications and timing of intervention. Indian Heart Journal, https://doi.org/10.1016/j.ihj.2019.07.006

4. Adhikari CM, Malla R, Shakya U, et al. Transcatheter closure of Patent ductus arteriosus at Shahid Gangalal National Heart Centre, Kathmandu, Nepal. Journal of Advances in Internal Medicine 2017;06(01):1-3.

5. Kulkarni S., Naidu R. Vascular ultrasound imaging to study immediate post catheterizati- on vascular complications in children. Catheter Cardiovasc Interv. 2006;68:450-455.

6. Saxena A., Gupta R., Kumar R.K. Predictors of arterial thrombosis after diagnostic cardiac catheterization in infants and children randomized to two heparin dosages. Cathet Cardiovasc Diagn. 1997;41:400-403.

7. Vitiello R, McCrindle BW, Nykanen D, Freedom RM, et al., Complications associated with pediatric cardiac catheterization. Journal of the American College of Cardiology, 1998 Nov; 32 (5): 1433-1440. https://doi. org/10.1016/S0735-1097(98)00396-9

8. Al-Akhfash AA, Almesned AA, Alqwaiee A. PDA Device Closure with and without Arterial Access. Interv Cardiol J. 2017; 3(2):61. doi: 10.21767/2471-8157.100061

9. Huang YQ, Huang Y, Huang D, Liu M, et al. Reliability of Echocardiography Measurement of Patent Ductus Arteriosus Minimum Diameter: A Metanalysis. International Journal of Cardiovascular and Cerebrovascular Disease, 2016; 4 (2): 1519

10. Karim T, Hussain MZ, Islam MT, Alam S., et al. Patent Ductus Arteriosus Size Estimation by Echocardiography and
Angiography: A Comparative Study. doi: 10.3329/bmrcb. v45i1.41803

11. Krichenko A, Benson LN, Burrows P, McLaughlin P, et al. Angiographic Classification of the Isolated, Persistently Patent Ductus Arteriosus and Implications for Percutaneous Catheter Occlusion. The American Journal of Cardiology, 1989; 63 (12): $877-880$

12. Ramaciotti C, Lemler MS, Moake L, Zellers TM. Comprehensive Assessment of Patent Ductus Arteriosus by Echocardiography Before Transcatheter Closure. Journal of the American Society of Echocardiography, 2002 Oct; 15 (10):1154-1159

13. Hiraishi S, Horiguchi Y, Fujino N, Agata Y et al. TwoDimensional and Doppler Echocardiographic Assessment of Variably Shaped Ductus Arteriosus by the Parasternal Approach. Pediatric Cardiol. 1991 Jan;12(1):6-12. doi:10.1007/BF02238490.

14. Wong JA, Shim D, Khoury PR, Meyer RA. Validation of Color Doppler Measurements of Minimum Patent Ductus Arteriosus Diameters: Significance for Coil Embolization. Am Heart J. 1998 Oct;136(4 Pt 1):714-7. doi: 10.1016/s00028703(98)70020-1.

15. Amoozgar H, Soltani M, Cheriki S. Estimation of Patent Ductus Arteriosus Diameters by Colour Doppler Echocardiography in Children. Cardiol Young. 2010 Dec;20(6):648-53. doi: 10.1017/S1047951110000879. 